\title{
The Ethics of Precision Rationing: Human Genetics and the Need for Debate on Stratifying Access to Medication
}

\author{
Alexis Walker ${ }^{a}$ Angie Boyce ${ }^{a}$ Priya Duggal $^{b}$ Chloe L. Thio ${ }^{c}$ Gail Geller ${ }^{a}$ \\ aBerman Institute of Bioethics, Johns Hopkins University, Baltimore, MD, USA; ${ }^{b}$ Department of Epidemiology, Johns \\ Hopkins School of Public Health, Baltimore, MD, USA; 'Department of Medicine, Johns Hopkins University School of \\ Medicine, Baltimore, MD, USA
}

\section{Keywords}

Rationing · Hepatitis C · Genetics · Genomics · Ethics

\begin{abstract}
Rising prices for new, transformative therapies are challenging health systems around the world, leading many payers and providers to begin rationing access to treatments, even in the countries that have been most resistant to doing so. This is the case for direct-acting antivirals (DAAs) for the treatment of hepatitis $C$ virus (HCV). However, little attention has been paid to the increasing role that human genetics might play in rationing decisions. Researchers have already proposed that genetic markers associated with spontaneous HCV clearance could be used to restrict DAA access for some patients, although treatment would be medically beneficial for those patients. Would such forms of rationing present a form of genetic discrimination? And what of the public health implications of these approaches? Here we present an ethical analysis of such proposals for "precision rationing" and raise 4 key areas of concern. We argue that ethical issues arising in this area are not substantively different from the pressing ethical issues regarding rationing and discrimina-
\end{abstract}

tion more broadly, but provide important impetus for motivating broad public debate to find ethically sound ways of managing genomics and new expensive medications.

(c) 2020 S. Karger AG, Basel

\section{Introduction}

A growing set of transformative therapies have recently offered new possibilities for improving population health globally, but rising prices for these therapies are challenging health systems around the world [1]. In an attempt to manage costs and treatment across populations, proposals are emerging for rationing access to treatments based on patients' genetics - confining access to the limited group of people likely to be most in need. In light of the rapid pace of genomics research and trends in drug pricing, it is quite feasible that such "precision rationing" would become increasingly common in addressing a variety of conditions. Such forms of geneticsbased rationing present pressing issues for health justice that require public debate before decisions are made to implement on a broad scale.

karger@karger.com
www.karger.com/phg
Karger ${ }^{\prime /}$

Alexis Walker

Berman Institute of Bioethics, Johns Hopkins University 1809 Ashland Ave.

Baltimore, MD 21205 (USA)

awalker@jhu.edu 
As an example, we consider the case of direct-acting antivirals (DAAs) for the treatment of hepatitis C. DAAs have transformed the treatment of hepatitis C virus (HCV), curing over $95 \%$ of patients with chronic HCV through a short, well-tolerated course of treatment, as opposed to older, extremely poorly tolerated interferon-based therapies with low success rates [2]. However, the high price of DAAs combined with their indication for nearly all of the 135 million chronic HCV patients worldwide has led to restrictions on their access in many locations, which we argue must be understood as rationing - constraining resource distribution in the context of insufficient resources, including by delaying treatment [3].

For some diseases, genetic indicators have enriched medical care by providing information about which drugs and courses of treatment are likely to be most effective for a specific patient $[4,5]$. However, recent proposals for DAA prioritization based on host genetics do not seek to find the most beneficial course of treatment. Rather, such proposals suggest disaligning treatment approaches from medical indication, in the interest of cost.

Amidst widespread debate on how to manage $\mathrm{HCV}$ treatment costs, some scholars and practitioners have argued that it is unethical to ration DAAs, instead calling for drug pricing systems that would allow more people to be treated at a lower cost per patient, to the mutual benefit of drug makers and patients $[6,7]$. However, little attention has been paid to the increasing role human genetics might play in rationing decisions. Researchers have already proposed that genetic markers associated with spontaneous HCV clearance or response to interferon could be used to restrict DAA access for some patients, although DAA treatment would be medically beneficial for those patients $[8,9]$. But what of the impacts these rationing efforts will have on the continued transmission of $\mathrm{HCV}$, and the associated public health implications? And would such rationing present a form of genetic discrimination in population health? Would making rationing decisions based on a person's genetics be ethically different from making those decisions based on other factors? The debate over DAAs highlights potential ethical issues of the future regarding rationing and human genetics; the case is specific to infectious diseases but has broader relevance. And while the rationing of DAAs may be of most direct relevance currently in low-income countries, even in high-income countries, one could imagine this type of rationing occurring in strongly resource-constrained settings, such as prison systems.

\section{Materials and Methods}

Review of emerging literature in genetics of hepatitis $\mathrm{C}$ revealed 2 papers proposing that patients could be prioritized or deprioritized for treatment based on genetic factors known to be associated with spontaneous clearance of $\mathrm{HCV}$ or with response to interferon-based treatments $[8,9]$. We then utilized a working group methodology $[10,11]$ to conduct a multidisciplinary ethics analysis, which capitalized on the authors' expertise in genetic epidemiology, infectious disease medicine, bioethics, and science and technology studies. For this analysis, each team member first identified relevant issues. Next, we elaborated on each issue based on theories of justice and structural inequality drawn from the fields of science and technology studies and bioethics [12-15]. While this is a specific body of theory, research from health technology assessment has suggested that ethics analysis based on divergent ethical theories derive comparable sets of issues [16].

The authorship team also conducted an additional search for proposals in the scientific literature sharing the above features, through a search of PubMed and Google Scholar in the date range January 2015-December 2019 for terms including "hepatitis C," "genetic," "stratify," and "prioritize." Of nearly five thousand hits, authors reviewed the top one hundred results. Rather than a systematic review, this informal search was meant to provide some context on how common such proposals have been in the literature over the past several years.

\section{Results}

Our search identified at least 11 papers sharing the features described above, with 10 of them published between the beginning of 2017 and end of 2019 [8, 9, 17-24]. According to these proposals, a patient who is slightly more likely to clear the virus without treatment (36 or $29 \%$ likelihood vs. $12 \%$ ) would not be given access to treatment initially [8], and patients with an elevated chance of response to interferon-based therapies $(50-80 \%$ vs. $20-$ $30 \%)$ could be directed to these less effective and poorly tolerated treatments [9].

Our ethics analysis highlighted 4 key areas of concern in rationing access to DAAs based on patients' genetic information. Notably, these 4 issues are shared with rationing based on nongenetic factors and include (1) drug pricing, (2) medical and public health relevance of the factors being used as a basis for rationing, (3) treatment options offered to deprioritized patients, and (4) healthcare inequalities and demographic patterns. We elaborate on each of these below:

1. The price of DAAs has been the most central factor in setting conditions for drug rationing. While some observers have argued that efforts to reduce pharmaceutical prices would result in a reduction in associated research and development, profits in the industry cur- 
rently heavily outweigh R\&D costs; scholars have emphasized that there is space to reduce pharmaceutical profits while still providing strong research incentives $[25,26]$. It is crucial that discussions of rationing foreground discussions on how to manage drug pricing, since sidelining pricing issues risks normalizing current approaches. These issues of pricing are significant regardless of the factors being used as a means of stratification, be they genetic information or otherwise.

2. Medical and public health relevance are also key considerations in the ethics of rationing. Patients with a history of injection drug use have been deprioritized from DAA treatment in many locations due to concerns over adherence. However, there is little medical or public health backing to such limitations on access. In fact, initial studies suggest that this group tends to be adherent to treatment and has low rates of reinfection [27]. Genetic factors related to disease progression, on the other hand, are likely to be of direct relevance to health outcomes.

3. The ethics of rationing also depend in large part on treatment options offered to deprioritized patients. One research group suggested that the IL28B genotype could be used to delay treatment for patients who have a slightly elevated genetic likelihood of spontaneous postpartum HCV clearance [8]. This would most likely represent a small delay in treatment for a subset of people - women while pregnant and in the year after giving birth [28]. However, another research group has suggested that patients with a higher genetic likelihood of response to interferon-based treatments could be directed to these substandard medications, even in the DAA era. The former proposal is much less ethically fraught than the latter, based on the treatment options offered to deprioritized patients. Nonetheless, there are significant issues in delaying treatment, including the public health impact of continued transmission before treatment, as well as psychosocial harms to patients who are unable to access treatment until their disease worsens [29].

4. Demographic patterns are likewise essential to considering the ethics of stratifying access to costly medications. IL28B genotypes have been found to vary by racial and ethnic group [30]. Similarly, factors including disease stage and history of drug use vary across demographics such as age and race/ethnicity. Rationing based on any one of these factors would differentially affect various social groups and could thus disproportionately affect members of a marginalized group. In the case of $\mathrm{HCV}$, the allele that has been proposed as a basis for delaying treatment is present in greater frequency in populations of European ancestry than those of African ancestry [30]. Deprioritization in this case would thus work against the grain of historical marginalization.

\section{Discussion}

At first glance, the idea of using patients' genetic information to ration access to beneficial treatment may raise concerns about discrimination based on genetic variation [31]. However, as seen above, rationing based on genetic information raises ethical issues that are in line with the pressing issues arising in rationing more broadly. In the case of hepatitis $\mathrm{C}$, genetic information may even present a less ethically problematic basis for rationing decisions, when compared to nongenetic factors that are currently being used to the detriment of marginalized groups such as injection drug users.

Just as genetic information provides probabilistic information about future disease course, so too do nongenetic factors currently being used as a basis for rationing, such as disease stage. With all such factors, determining what counts as a high enough likelihood to merit a specific action requires weighing probabilities based on the factors described here, including impacts on health equity, public health, patients' psychosocial wellbeing, etc. The moral acceptability of a threshold for deprioritizing certain patients from treatment relies on principles of justice, and ought to err on the side of prioritizing the marginalized, according to the theories of equity described above. Because both genetic and nongenetic factors related to disease progression are unevenly distributed across populations (e.g., by age or race), prioritizing based on any factor would differentially affect those groups. For example, if a genetic factor related to a favorable disease outcome (e.g., spontaneous clearance and slower disease progression) were understood to be more common in people of African descent than other groups, and that factor was used to deprioritize patients from treatment, this would lead to disproportionate impact on a population that has been historically oppressed in much of the world. It is thus crucial to consider whether stratifying access based on any factor implicitly deprioritizes marginalized groups because of the ways that the factor is distributed across populations.

The ethics here turn on debates about rationing writ large. While many people argue that drug prices need to be lower so that more people can be treated, or that health 
systems need to invest more to cover all patients, other observers argue that decisions about resource allocation are part of any health system. Broad debate of these issues is necessary, and the global dynamics of drug pricing require that this debate have an international element.

We have raised 4 essential areas of concern, which lead to a series of 4 questions that should inform any discussion about rationing, regardless of whether it is based on genetic factors. These are questions of judgment requiring discussion amongst various stakeholders:

1. Have substantial efforts been made to curb this drug's prices in the long and short term?

2. What is the clinical and public health relevance of factors used for prioritization?

3. What harms (including psychosocial and dignitary harms associated with treating people differently based on economic environment) are involved in treatment alternatives offered to deprioritized patients?

4. What impact will rationing decisions have on health inequalities?

Guided by these questions, broad public debate on the ethical issues presented by stratifying access to medication in the genomic era is crucial to addressing inequalities in healthcare.

\section{Statement of Ethics}

As a secondary analysis, this study does not constitute research with human subjects.

\section{Disclosure Statement}

The authors have no conflicts of interest to declare.

\section{Funding Sources}

This research has been funded by the National Human Genome Research Institute.

\section{Author Contributions}

Dr. Walker led study design, analysis, and drafting of the manuscript. Dr. Boyce made substantial contributions to study design, analysis, and manuscript writing. Dr. Thio made substantial contributions to the conceptualization of the study, analysis, and manuscript writing. Doctors Duggal and Geller made substantial contributions to analysis and manuscript writing.

\section{References}

1 Cox C, Kamal R, Jankiewicz A, Rousseau D; for the Kaiser Family Foundation. Recent trends in prescription drug costs. JAMA. 2016;315(13):1326.

2 Falade-Nwulia O, Suarez-Cuervo C, Nelson DR, Fried MW, Segal JB, Sulkowski MS. Oral direct-acting agent therapy for hepatitis $\mathrm{C}$ virus infection: a systematic review. Ann Intern Med. 2017;166(9):637-48.

3 Iserson JC, Moskop J. Triage in medicine, part I: concept, history, and types. Ann Emerg Med. 2007;49(3):275-81.

4 Kangelaris KN, Bent S, Nussbaum RL, Garcia DA, Tice JA. Genetic testing before anticoagulation? A systematic review of pharmacogenetic dosing of warfarin. J Gen Intern Med. 2009;24(5):656-64.

5 Alsop K, Fereday S, Meldrum C, deFazio A, Emmanuel C, George J, et al. BRCA mutation frequency and patterns of treatment response in BRCA mutation-positive women with ovarian cancer: a report from the Australian Ovarian Cancer Study Group. J Clin Oncol. 2012;30(21):2654-63.

6 Edlin B. Access to treatment for hepatitis C virus infection: time to put patients first. Lancet Infect Dis. 2016;16(9):e196-201.
7 Sood N, Ung D, Shankar A, Strom BL. A novel strategy for increasing access to treatment for hepatitis $\mathrm{C}$ virus infection for medicaid beneficiaries. Ann Intern Med. 2018;169(2): 118-9.

8 Hashem M, Jhaveri R, Saleh DA, Sharaf SA, El-Mougy F, Abdelsalam L, et al. Spontaneous viral load decline and subsequent clearance of chronic hepatitis $C$ virus in postpartum women correlates with favorable interleukin-28B gene allele. Clin Infect Dis. 2017;65(6):9991005 .

9 Duffy D, Mottez E, Ainsworth S, Buivan TP, Baudin A, Vray M, et al. An in vitro diagnostic certified point of care single nucleotide test for IL28B polymorphisms. PLoS One. 2017; 12(9):e0183084.

10 Fawcett E. Working group on ethical considerations in science and scholarship. Account Res. 1993;3(1):69-72.

11 Adler D, Zlotnik Shaul R. Disciplining bioethics: towards a standard of methodological rigor in bioethics research. Account Res. 2012; 19(3):187-207.

12 Beauchamp T, Walters L. Contemporary issues in bioethics. 6th ed. New York: Wadsworth; 2003.

13 Rawls J. A theory of justice. Cambridge, MA: Harvard University Press; 1971.
14 Farmer P. An anthropology of structural violence. Curr Anthropol. 2004;45(3):305-25.

15 Turner L. Bioethics, social class, and the sociological imagination. Camb Q Healthc Ethics. 2005;14(4):374-8.

16 Saarni SI, Braunack-Mayer A, Hofmann B, van der Wilt GJ. Different methods for ethical analysis in health technology assessment: an empirical study. Int J Technol Assess Health Care. 2011;27(4):305-12.

17 Micu IS, Musat M, Hamidi YA, Dumitru A, Rogoveanu A, Popoiag RE. IL-28B: predictor of sustained virological response for IFNbased regimens in chronic hepatitis $\mathrm{C}$ and criteria for optimizing DAAs indication. Rev Chim. 2019;70(11):3964-6.

18 Medrano LM, Jiménez-Sousa MA, Fernández-Rodríguez A, Resino S. Genetic polymorphisms associated with liver disease progression in HIV/HCV-coinfected patients. AIDS Rev. 2017;19(1):3-15.

19 Trinks J, Caputo M, Hulaniuk ML, Corach D, Flichman D. Hepatitis C virus pharmacogenomics in Latin American populations: implications in the era of direct-acting antivirals. Pharmgenomics Pers Med. 2017;10:79-91.

Walker/Boyce/Duggal/Thio/Geller 
20 Choi J, Lim YS. Genetic-based risk assessment for hepatocellular carcinoma in patients with hepatitis C: where do we stand? EBioMedicine. 2017;15:6-7.

21 Zidan HE, Talaat RM, Ammaar A, Sakr MA. Interferon-lambda 4 gene polymorphisms predict treatment response in Egyptian HCV genotype 4 patients exposed to radiation. Egypt J Hosp Med. 2019;77(1):4748-53.

22 Lamoury FM, Bartlett S, Jacka B, Hajarizadeh $B$, Grebely J, Matthews GV, et al. Interferon $\lambda$ 3 and 4 genotyping using high-resolution melt curve analysis suitable for multiple clinical sample types. J Mol Diagn. 2015;17(5): 583-9.

23 Jiménez-Sousa MA, Berenguer J, García-Álvarez $M$, Gutierrez-Rivas $M$, Aldámiz-Echevarria $T$, Tejerina $F$, et al. Impact of patatinlike phospholipase domain-containing 3 gene polymorphism (rs738409) on severity of liver disease in HIV/hepatitis C virus-coinfected patients. AIDS. 2016;30(3):465-70.
24 Aisyah DN, Shallcross L, Hully AJ, et al. Host genetic factors associated with hepatitits $\mathrm{C}$ spontaneous viral clearance: a meta-analysis. Gut. 2019;68(Suppl 1):A1-A66.

25 Light DW, Lexchin JR. Pharmaceutical research and development: what do we get for all that money? BMJ. 2012;345:e4348.

26 Kesselheim AS, Avorn J, Sarpatwari A. The high cost of prescription drugs in the United States: origins and prospects for reform. JAMA. 2016;316(8):858-71.

27 Aspinall EJ, Corson S, Doyle JS, Grebely J, Hutchinson SJ, Dore GJ, et al. Treatment of hepatitis $\mathrm{C}$ virus infection among people who are actively injecting drugs: a systematic review and meta-analysis. Clin Infect Dis. 2013; 57(Suppl 2):S80-9.
28 El-Kamary SS, Hashem M, Jhaveri R, ElGhazaly H. Reply to Walker et al. Clin Infect Dis. 2018;67(6):984.

29 Harris M. Managing expense and expectation in a treatment revolution: problematizing prioritisation through an exploration of hepatitis C treatment "benefit". Int J Drug Policy. 2017; 47:161-8.

30 Ge D, Fellay J, Thompson AJ, Simon JS, Shianna KV, Urban TJ, et al. Genetic variation in IL28B predicts hepatitis C treatment-induced viral clearance. Nature. 2009;461(7262):399_ 401.

31 Billings PR, Kohn MA, de Cuevas M, Beckwith J, Alper JS, Natowicz MR. Discrimination as a consequence of genetic testing. Am J Hum Genet. 1992;50(3):476-82. 